\title{
Current impact of ceased journals: are they still alive?
}

\author{
Marijan Šember, Lea Škorić and Jelka Petrak \\ University of Zagreb School of Medicine, \\ Central Medical Library \\ 10000 Zagreb, Šalata 3, CROATIA \\ e-mail: marijan.sember@mef.hr; \\ lea.skoric@mef.hr (corresponding author); jelka.petrak@mef.hr
}

\begin{abstract}
This article presents a citation analysis of papers published between 1909 and 1954 by two ceased journals covering the abandoned field of eugenics. The aim of the study was to investigate the visible signs of current scientific impact of these old papers and find out if they are significant for reasons other than historical referencing. Our survey involved a three-stage citation analysis using the Web of Science Core Collection and content analysis of the citing papers. The citation counts were collected and classified by the citing years. Papers that had 25 or more citations from 2000 to 2014 were selected for further analysis and examined for their citations in 2014. This produced 941 papers citing 24 papers published between 1915 and 1954, 23 of which were published by the Annals of Eugenics, and one by the Eugenics Review. Four of the cited articles accounted for 87 percent of all citations received. Due to not all citing papers (941) published in 2014 were available in full text, only 70 percent of them were analysed using content analysis technique to examine and classify the reasons for citing. The findings suggest that these old journals left a strong scientific imprint with papers whose impact has been increased in the last decades. They were less cited because of the scientific problems they addressed at the time of publishing. In contrast, these papers were cited due to their innovative research methodologies that have become valuable instruments in many scientific disciplines that emerged later. This study is significant in giving additional insight in the citation pattern of older papers.
\end{abstract}

Keywords: Old periodicals; Citation counts; Content-based citation analysis; Journal studies; Eugenics.

\section{INTRODUCTION}

With so much scientific literature published each year, why do older papers continued to be cited? Citations are the standard means by which authors acknowledge the source of their methods, ideas, and findings and are often used as a rough measure of a paper's importance (Van Noorden, Maher and Nuzzo 2014). Garfield (1975) noted that each scientific discipline has its own protocol regarding citations, but according to Gupta (1997), there is a factor that appears to be universal in citation practices - that references to the past literature are distributed randomly irrespective of the time of publication; however a majority will always relate to fairly recent papers. Oppenheim and Renn (1978) found that the reasons for about 40 percent of citations to the old papers were purely historical. Given this context, the aim of this study is to give an additional insight in the citation pattern of older papers using the example of journals covering an abandoned field of eugenics which ceased publishing many years ago. 
The term "eugenics" was coined in 1883 by Francis Galton, indicating "the study of the agencies under social control that may improve or impair the racial qualities of future generations either physically or mentally" (quoted in Gaither and Cavazos-Gaither 2012, p. $684)$. In the early $20^{\text {th }}$ century, eugenics became a serious scientific discipline pursued by both biologists and social scientists. Eugenics researchers believed that by studying large human families in which a certain undesirable trait appeared, they could demonstrate a genetic pattern of inheritance for the trait, and such findings would justify policies aimed at removing the related genes from the population (Norrgard 2008).

From the very beginning, the doctrine had strong opponents. Pearl (1927) described it as "a mingled mess of ill-grounded and uncritical sociology, economics, anthropology, and politics, full of emotional appeals to class and race prejudices, solemnly put forth as science, and unfortunately accepted as such by the general public" (p.260). However, eugenics was not overthrown in the scientific arena (Paul and Spencer 1995), and the major causes of its decline after the World War II were political. Although it became stigmatised and considered as a failed pseudoscience, some authors believe that the underlying ideas have not disappeared, and that eugenics, as a concept, has played an important role in the development of new scientific disciplines (Ramsden 2006) such as genetic engineering as well as methods applied in disciplines such as statistics, demography, genetics, and psychometrics.

The US National Library of Medicine Serials Catalog (NLM Catalog 2015) contains seven records of journals issued by various eugenics societies that were launched between 1909 and 1935. Three of them had long and respectable publishing history. The oldest is the Eugenics Review from 1909. This quarterly journal was published in London by the Eugenics Education Society (later Eugenics Society) until 1968. The Eugenical News was published from 1916 to 1953 by the American Eugenics Society, Cold Spring Harbor NY Eugenics Record Office, and Eugenic Research Association. It was superseded by the Eugenics Quarterly in 1954. The Annals of Eugenics started in London in 1925 and was issued by the Galton Laboratory for National Eugenics and Eugenics Society until 1954. In 1954, it changed its title to Annals of Human Genetics. The proclaimed journals' core subjects were biology (especially heredity and selection), anthropology, racial problems, politics, religion and environment. Since these journals stopped their scientific activity more than sixty years ago, they provide an interesting example for citation patterns analysis.

\section{LITERATURE REVIEW}

Larivière et al. (2008) studied the evolution of the aging phenomenon of cited literature and its changes over more than 100 years of scientific activity. The major finding of their study is that contrary to a widely held belief, the age of cited material has risen continuously since the mid-1960s. Their data suggest that in the fields of natural sciences and engineering, the importance of papers aged between 21 and 50 years has increased tremendously since the beginning of the 1970s. These older papers are not excluded from the science system but rather still play an active role in it. However, very old papers (i.e. those aged 51-100 years) have seen their importance decrease since World War II (Larivière et al. 2008).

Verstak et al. (2014) recently documented the growing impact of the older literature, emphasising that digitisation made it easily available. On the contrary, Davis and Cochran 
(2015) argued that the trend to cite older papers is not fully explained by technology (such as digital publishing, search and retrieval), but may be the result of a structural shift to fund incremental and applied research over fundamental science.

Citing behaviour is not always motivated by the wish to acknowledge intellectual and cognitive influences of colleague scientists (Bornmann and Daniel 2008). This is why simple counting of citations is often complemented with more complex content-based citation analysis. Giving an overview of content-based citation analysis at both syntactic and semantic levels, Ding et al. (2014) emphasised that the main utility of such analysis is the interpretation of a citation's value in the context of the scientific paper rather than its simple frequency. Since current research articles are predominantly structured into sections, i.e. introduction, methods, results, discussion, and conclusion(s), it became possible to analyse a citation's usefulness based on its location within the section. The first results of such content-based syntactic analysis were published by Voos and Dagaev (1976), showing that it is possible to use the location of the cited article as indicator of its value for the author of the citing publication. Maričic et al. (1998) ranked highest the citations in the methods or results section, followed by citations in discussion and finally in introduction. In another study, Herlach (1978) concluded that the repeated mention of a given reference in the same research paper indicated a closer relationship of the citing to the cited paper.

Studies examining citation reasons and functions employ classification schemes. Comparing the history and contextual importance of eleven highly cited articles in the field of molecular genetics, McCain and Turner (1989) developed a classification scheme based on the assumption that a citation in a method section of a research paper was more important than one in the introduction section. Hanney et al. (2005) designed a complex model for identifying the importance of citations in a paper combining the number of citation occurrences and their locations in the text with the reasons behind each of them (develop, support, apply, refute, note/review only). They classified the importance of the cited papers as peripheral, limited, considerable, and essential.

Oppenheim and Renn (1978) analysed 23 highly cited pre-1930 papers in the fields of physics and physical chemistry and proposed a scheme with seven categories. They classified the reasons for citation as follows: a) historical background; b) description of other relevant work; c) supplying information or data, other than for comparison; d) supplying information or data for comparison; e) use of theoretical equation; f) use of methodology, and g) theory or method not applicable or not the best one.

\section{OBJECTIVES AND METHODS}

This study aims to examine the current echo of the leading eugenics journals, which stopped their publishing activity more than 60 years ago. Our idea was to separate articles cited in historical context alone from those that still have an impact on active scientists and their research. The study attempts to answer the following research questions:

a) Is there any current scientific impact of the papers published by the journals that covered controversial topics and ceased publishing many years ago?

b) What are the reasons for citing these old articles?

c) What is the character of the most highly cited old papers? 
We decided to analyse the papers published by three eugenics journals from their first issues until the beginning of 1954 for several reasons. The support for eugenics began to decline in the mid-1950s and some authors set the discovery of the DNA structure by Watson and Crick in 1953 as a separation line between the old and the new eugenics (Matulić 2005; Wiesenthal and Wiener 1999). The Eugenical News was discontinued in 1953, and the last issue of the Annals of Eugenics appeared in March 1954. The Eugenics Review continued to publish until 1968, but the last issue we decided to include was published in January 1954 in Volume 45, Number 4).

The first stage of our research was to find citations of articles published in the analysed period. The citation research was done in February 2015 using the Thomson Reuters' Web of Science Core Collection (2015) database available to Croatian academic institutions. We used the Citing Reference Search function covering the period from 1955 onwards. The search was performed using the abbreviated journal names in the "cited work" search field. All misquotations (year, volume, pages) were properly managed and later included in the analysis. From the search results we singled out the articles that had 25 or more citations from 2000 to 2014. This threshold for identifying highly cited papers was proposed by Plomp (1990). Papers that had 25 or more citations from 2000 to 2014 were selected for further analysis and examined for their citations in 2014.

The second stage of our research was focussed on inspecting the content of the citing articles in order to find out the reasons for citations. The analysis was done on the 2014 sample of the citing articles because the most recent citations are a visible sign of the current scientific impact of the cited articles. We made a list of citing articles for each original paper and located full texts of more than 70 percent of all citing papers. The text and the bibliography of each available paper were examined to ensure that the respective cited article was indeed used and mentioned.

Looking for the reasons for citing the articles published in the analysed journals, we found the classification by Oppenheim and Renn (1978) especially useful, since it was developed for the analysis of reasons for citing very old papers. We modified that scheme and classified the citing articles in five categories:

a) Historical reasons (first contribution to particular research problem, simple mention of the work, or as one of many cited contributing papers);

b) Detailed description of the facts and theories already known in the field, and/or explanation of methodology or findings in the cited paper, but not used as a method in the citing paper, nor for comparison of results;

c) Use of methods, mathematical models, quotations and calculations found in the cited article;

d) Quantitative and/or qualitative comparison of the results; and

e) Critical examination.

As an illustration of our classification method, we give an example of Fisher's paper published in the Annals of Eugenics in 1936.

Category 1: "These nonlinear methods have some advantages over linear methods such as PCA [15] and linear discriminant analysis [9]" (Kim and Lee 2014).

Category 2: "Discriminant analysis was introduced by Ronald Fisher (7) for two class problems (Fisher discriminant analysis, FDA) and remains to be one of the most popular methods for dimensionality reduction" (Nava et al. 2014). 
Category 3: "This is done by using Fisher's Linear Discriminant (FLD)" (Li et al. 2014).

Category 4: "In this experiment we exemplify how well FBN perform as a classifier when in the presence of sparse training examples, by comparing it with several other classifiers. We use the very well known Iris flower dataset as a benchmark" (Tome and Carvalho 2014).

Category 5: "Results showing the 2-D visualization and classification performance of the data demonstrate that the extended TR-LDA method achieves better performance than other algorithms, such as PCA, LPP, MMC, CCA LDA, and MFA, in fault diagnosis" (Jin et al. 2014).

We expected the first two categories of citations to be found mainly in the introduction section, the third in the methods section, and the fourth and fifth in the results/discussion sections. If a citing article had two or more references to the same old article in different sections, we opted for the more relevant category. In the third stage, we focused on in depth analysis of the four most cited articles.

\section{RESULTS}

The first-stage search results showed that all cited original articles were published by two of the analysed journals, Eugenics Review and Annals of Eugenics. Only three papers in Eugenical News were cited in the analysed period, and not a single one had $\geq 25$ citations, which excluded the journal from further analysis. The Eugenics Review published 1271 items, including all types of contributions (Vol. 1, no. 1, 1909-Vol. 45, no. 4, 1954), nine of which had $\geq 25$ citations ( 0.7 percent). However, only one paper had $\geq 25$ citations from 2000 to 2014. The Annals of Eugenics published 516 items between 1925 and 1954. Of these, 147 papers ( 28.5 percent) had $\geq 25$ citations and 23 of them $\geq 25$ citations from 2000 to 2014 (Table 1). These results suggest that the Annals of Eugenics was the most virulent journal in terms of current scientific impact. Six papers stood out from the rest with more than a half of their total citation score pertaining to the last 15 years. If we single out Fisher's (1936) and Kosambi's (1944) papers, this share is even higher, exceeding 70 percent.

The second stage of our research employed content analysis approach to examine the citing articles published in 2014. Our query in the Web of Science Core Collection produced 941 papers citing 24 papers published between 1915 and 1954 (Table 1), 23 of which were published by the Annals of Eugenics, and one by the Eugenics Review. Four articles accounted for 87 percent of all citations.

We examined the full texts of 662 (70 percent) of the identified citing articles that were available online and classified the reasons for citing using our five-category scheme (Table 1).

It is well known that methodological papers proposing successful techniques, methods, or approximations can generate a large number of citations (Wikipedia contributors, " $h$ index", 2015). The most cited papers in our analysis are undoubtedly of that kind (67 percent) (Figure 1). The number of articles citing the results for comparison was very low (5 percent), and, given the controversial nature of the discipline, we were surprised to find only three articles citing the original paper for the reason of critical examination. 
Table 1: Papers with $\geq 25$ Citations in the Web of Science Core Collection (WoSCC) since 2000 and their Classification according to Reasons for Citation

\begin{tabular}{|c|c|c|c|c|c|c|c|c|c|c|c|c|c|}
\hline No. & Author, Year & Journal & Title of Paper & $\begin{array}{c}\text { All } \\
\text { citations }\end{array}$ & $\begin{array}{c}\text { Citations } \\
1955- \\
2014\end{array}$ & $\begin{array}{c}\text { Citations } \\
2000- \\
2014\end{array}$ & $\begin{array}{l}\text { Citations } \\
\text { in } 2014\end{array}$ & $\begin{array}{l}\text { Citing } \\
\text { papers }\end{array}$ & $\begin{array}{c}\text { Category } \\
1\end{array}$ & $\begin{array}{l}\text { Category } \\
\mathbf{2}\end{array}$ & $\begin{array}{c}\text { Category } \\
3\end{array}$ & $\begin{array}{c}\text { Category } \\
\quad 4\end{array}$ & $\begin{array}{l}\text { Category } \\
5\end{array}$ \\
\hline 1 & Kosambi, 1944 & Annals of Eugenics & $\begin{array}{l}\text { The estimation of map distances from } \\
\text { recombination values }\end{array}$ & 3506 & 3363 & 2624 & 249 & 213 & 0 & 0 & 213 & 0 & 0 \\
\hline 2 & Wright, 1951 & Annals of Eugenics & The genetical structure of populations & 3952 & 3832 & 2513 & 182 & 151 & 20 & 17 & 92 & 21 & 1 \\
\hline 3 & Fisher, 1936 & Annals of Eugenics & $\begin{array}{l}\text { The use of multiple measures in } \\
\text { taxonomic problems }\end{array}$ & 5175 & 3724 & 2347 & 246 & 126 & 24 & 18 & 79 & 4 & 1 \\
\hline 4 & Fisher, 1937 & Annals of Eugenics & $\begin{array}{l}\text { The wave of advance of advantageous } \\
\text { genes }\end{array}$ & 2038 & 1915 & 1376 & 142 & 103 & 43 & 15 & 40 & 5 & 0 \\
\hline 5 & Fisher, 1941 & Annals of Eugenics & $\begin{array}{l}\text { Average excess and average effect of } \\
\text { a gene substitution }\end{array}$ & 547 & 521 & 290 & 31 & 19 & 3 & 14 & 0 & 1 & 1 \\
\hline 6 & Fisher, 1938 & Annals of Eugenics & $\begin{array}{l}\text { The statistical utilization of multiple } \\
\text { measurements }\end{array}$ & 424 & 297 & 128 & 14 & 6 & 0 & 0 & 6 & 0 & 0 \\
\hline 7 & Smith, 1936 & Annals of Eugenics & $\begin{array}{l}\text { A discriminant function for plant } \\
\text { selection }\end{array}$ & 366 & 347 & 89 & 8 & 8 & 5 & 2 & 1 & 0 & 0 \\
\hline 8 & Fisher, 1935 & Annals of Eugenics & $\begin{array}{l}\text { The fiducial argument in statistical } \\
\text { inference }\end{array}$ & 204 & 166 & 81 & 8 & 2 & 1 & 0 & 1 & 0 & 0 \\
\hline 99 & Fisher, 1934 & Annals of Eugenics & $\begin{array}{l}\text { The effect of methods of } \\
\text { ascertainment upon the estimation of }\end{array}$ & 232 & 202 & 81 & 5 & 3 & 2 & 0 & 1 & 0 & 0 \\
\hline 10 & Fisher, 1915 & Eugenics Review & The evolution of sexual preference & 135 & 122 & 78 & 9 & 6 & 3 & 3 & 0 & 0 & 0 \\
\hline 11 & Bose, 1939 & Annals of Eugenics & $\begin{array}{l}\text { On the construction of balanced } \\
\text { incomplete block designs }\end{array}$ & 295 & 244 & 70 & 8 & 3 & 1 & 0 & 2 & 0 & 0 \\
\hline 12 & Cochran, 1941 & Annals of Eugenics & $\begin{array}{l}\text { The distribution of the largest of a set } \\
\text { of estimated variances as a fraction of }\end{array}$ & 233 & 213 & 70 & 8 & 7 & 0 & 0 & 7 & 0 & 0 \\
\hline 13 & Haldane, 1947 & Annals of Eugenics & $\begin{array}{l}\text { The mutation rate of the gene for } \\
\text { haemophilia and its segregation ratios }\end{array}$ & 179 & 162 & 59 & 2 & 1 & 0 & 1 & 0 & 0 & 0 \\
\hline 14 & Penrose, 1935 & Annals of Eugenics & $\begin{array}{l}\text { The detection of autosomal linkage in } \\
\text { data which consists of pairs of }\end{array}$ & 214 & 181 & 58 & 0 & 0 & 0 & 0 & 0 & 0 & 0 \\
\hline
\end{tabular}




\begin{tabular}{|c|c|c|c|c|c|c|c|c|c|c|c|c|c|}
\hline & Author, Year & Journal & Title of Paper & $\begin{array}{c}\text { All } \\
\text { citations }\end{array}$ & $\begin{array}{l}\text { Citations } \\
\text { 1955- }\end{array}$ & $\begin{array}{l}\text { Citations } \\
\text { 2000- }\end{array}$ & $\begin{array}{l}\text { Citations } \\
\text { in } 2014\end{array}$ & $\begin{array}{l}\text { Citing } \\
\text { papers }\end{array}$ & $\begin{array}{c}\text { Category } \\
1\end{array}$ & $\begin{array}{l}\text { Category } \\
\mathbf{2}\end{array}$ & $\begin{array}{c}\text { Category } \\
\mathbf{3}\end{array}$ & $\begin{array}{c}\text { Category } \\
4\end{array}$ & $\begin{array}{l}\text { Category } \\
5\end{array}$ \\
\hline 15 & Harris, 1949 & Annals of Eugenics & $\begin{array}{l}\text { The measurement of taste sensitivity } \\
\text { to phenylthiourea. (P.T.C.) }\end{array}$ & 427 & 411 & 53 & 4 & 3 & 0 & 1 & 2 & 0 & 0 \\
\hline 16 & Karn, 1951 & Annals of Eugenics & $\begin{array}{l}\text { Birth weight and gestation time in } \\
\text { relation to maternal age, parity and }\end{array}$ & 306 & 284 & 45 & 2 & 1 & 0 & 1 & 0 & 0 & 0 \\
\hline 17 & Penrose, 1948 & Annals of Eugenics & $\begin{array}{l}\text { The problem of anticipation in } \\
\text { pedigrees of dystrophia myotonica }\end{array}$ & 228 & 219 & 44 & 3 & 2 & 0 & 2 & 0 & 0 & 0 \\
\hline 18 & Bennett, 1954 & Annals of Eugenics & On the theory of random mating & 103 & 102 & 42 & 1 & 1 & 1 & 0 & 0 & 0 & 0 \\
\hline 19 & Fisher, 1940 & Annals of Eugenics & $\begin{array}{l}\text { The precision of discriminant } \\
\text { functions }\end{array}$ & 183 & 146 & 40 & 8 & 2 & 1 & 1 & 0 & 0 & 0 \\
\hline 20 & Haldane, 1946 & Annals of Eugenics & The interaction of nature and nurture & 113 & 97 & 39 & 3 & 2 & 1 & 1 & 0 & 0 & 0 \\
\hline 21 & Haldane, 1949 & Annals of Eugenics & $\begin{array}{l}\text { The association of characters as a } \\
\text { result of inbreeding and linkage }\end{array}$ & 98 & 90 & 31 & 2 & 1 & 1 & 0 & 0 & 0 & 0 \\
\hline 22 & Fisher, 1941 & Annals of Eugenics & The negative binomial distribution & 159 & 137 & 30 & 4 & 1 & 0 & 1 & 0 & 0 & 0 \\
\hline 23 & Barnicot, 1951 & Annals of Eugenics & $\begin{array}{l}\text { Taste thresholds of further eighteen } \\
\text { compounds and their correlation with }\end{array}$ & 48 & 47 & 28 & 1 & 1 & 1 & 0 & 0 & 0 & 0 \\
\hline 24 & Sukhatme, 1937 & Annals of Eugenics & $\begin{array}{l}\text { Tests of significance for samples of } \\
\text { the chi(2)-population with two }\end{array}$ & 70 & 58 & 26 & 1 & 0 & 0 & 0 & 0 & 0 & 0 \\
\hline & & & Total & 19235 & 16880 & 10242 & 941 & 662 & 107 & 77 & 444 & 31 & 3 \\
\hline
\end{tabular}




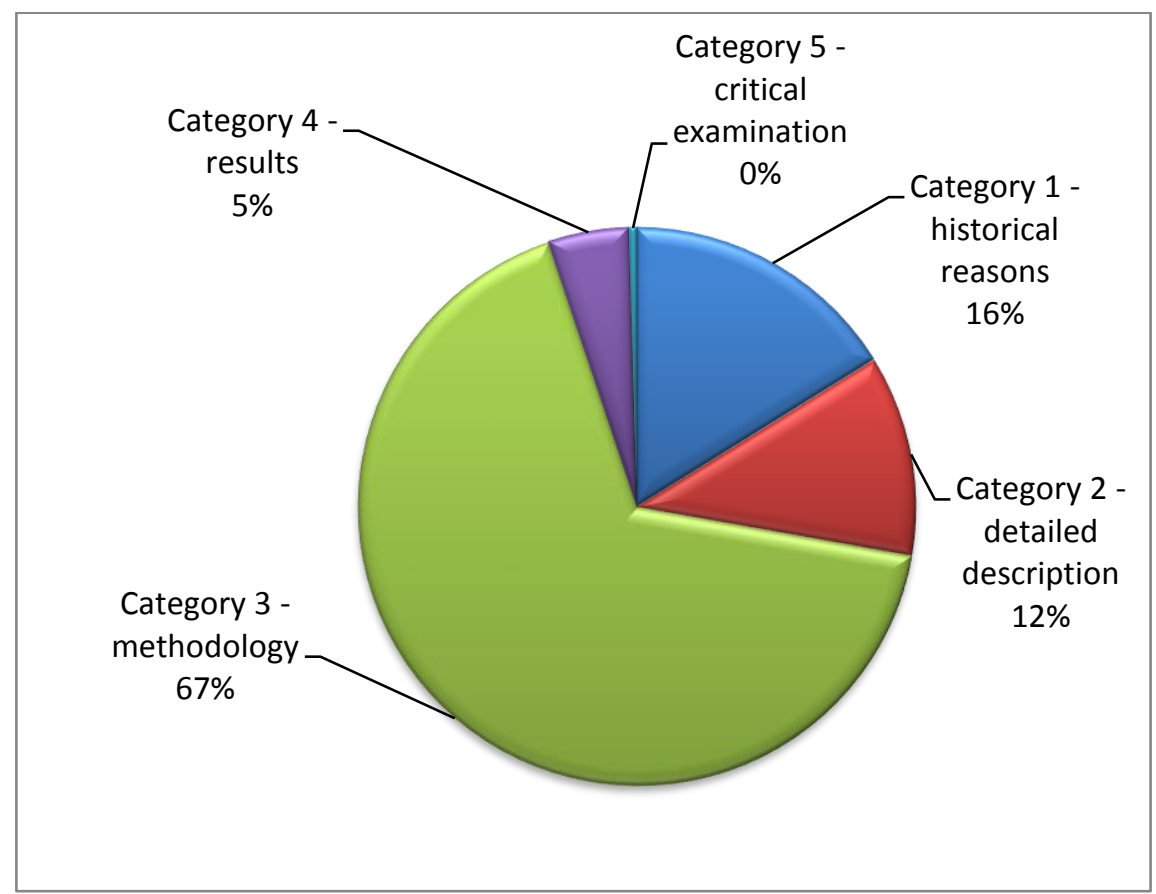

Figure 1: Reasons for Citing in 2014 according to the Five-Category Scheme

The most cited papers: Fisher, Wright, and Kosambi

We identified four articles that stood out from the others in terms of number of citations received (Figure 2).

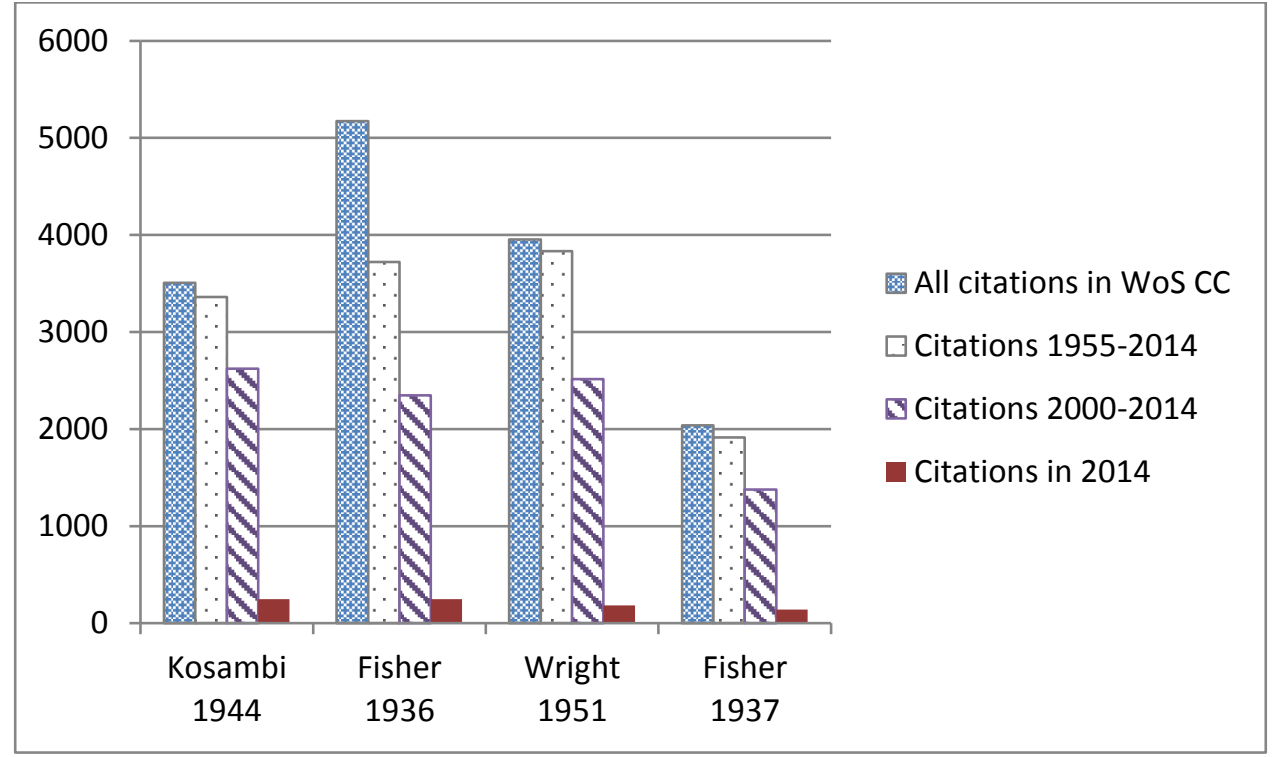

Figure 2: Four Most Cited Papers Ranked by the Number of Citations in the Web of Science (WoS) Core Collection in 2014

The first two articles were by Sir Ronald A. Fisher (Wikipedia contributors, "Ronald Fisher", 2015), English statistician, evolutionary biologist, mathematician, geneticist, and eugenicist, who was an important figure in the British wing of the eugenic movement. He 
had been the editor in chief of the Annals of Eugenics for 20 years (1934-1954). When Fisher became the editor of the Annals, it was subtitled "Statistical studies in genetics and human inheritance" (Weiss and Lambert 2011). Hald (2004) called him "a genius who almost single-handedly created the foundations for modern statistical science" (p.147), because Fisher pioneered the application of statistical procedures to the design of scientific experiments. According to an Internet source, Fisher is "the most influential scientist ever" (Fisher 2012).

In "The use of multiple measurements in taxonomic problems" Fisher (1936) introduced and developed a linear discriminant model to distinguish the species from each other. The linear discriminant analysis (LDA) based on Fisher's model has been widely used in statistics, pattern recognition, and machine learning to find a linear combination of features which characterises or separates two or more classes or objects (Wikipedia contributors, "Linear discriminant analysis", 2015). From 1955 to 2014, this paper garnered a total of 3724 citations in the Web of Science Core Collection. More than 60 percent of the citations were received from 2000 to 2014, 246 of which in 2014 alone. We inspected the full texts of 126 citing papers and found that the authors of 63 percent of the papers cited Fisher's model in the methodology section. We classified 60 percent of these papers as those that adopt the method or approach of the cited author (Category 3). Nineteen percent of the analysed papers mentioned Fisher's paper in the introduction or related section for historical reasons or as a previous work (Category 1), and 14 percent described or discussed the cited paper in more detail (Category 2).

We believe that such a large number of citations between 2000 and 2014 is owed to new applications of Fisher's model across a range of disciplines such as electronics, computer science, and robotics.

In "The wave of advance of advantageous genes" Fisher (1937) proposed the equation (Fisher's equation or Fisher-KPP equation) for describing the spatial spread of an advantageous allele and explored its travelling wave solutions in the context of population dynamics (Wikipedia contributors, "Fisher's equation", 2015). This article received an impressive number of 1376 citations from 2000 to 2014, or 72 percent of all citations in the analysed period. Of the 142 citing articles published in 2014, we examined 103 full texts. Roughly half of them mentioned this Fisher's paper as a pioneering contribution, and the other half used his equation as a calculation model or as the basis for the development of their own methodology. The citations were found in journals covering various research fields such as applied mathematics, population genetics, and macroeconomics.

One of the top four cited articles was "The genetical structure of population", authored by Sewall Wright (1951), who was a dominant figure in population genetics. He was on the Advisory Board of the American Eugenics Society, but, according to Provine (1986), Wright never published on eugenics and did not believe that eugenics would achieve the intended benefits for mankind.

In a Citation Classic commentary published in Current Contents, Crow (1989) described this paper as a summary of the "ways in which population structure can lead to random genefrequency changes, both in domestic livestock and in natural populations" (p.17). He commented that an appendix to this article that describes Wright's method of path analysis and its applications in population genetics was especially useful. From 1955 to 2014, this paper received 3832 citations in the Web of Science Core Collection, 66 percent (2513) of which after 2000. We found 182 citing articles in 2014 and analysed 151 full texts 
(83 percent). Sixty-one percent of the citing articles mentioned Wright's paper in the methods section and we classified all of these papers as category 3, as they used "a practical or theoretical technique given in the cited paper" (Oppenheim and Renn 1978, p.226). Introductions accounted for the rest of the citations, and we classified them all as category 1 - pioneering works in the field.

The most cited paper between 2000 and 2014 was "The estimation of map distances from recombination values", authored By Damodar D. Kosambi (1944), an Indian mathematician, statistician, historian, and polymath, who contributed to genetics by introducing the Kosambi mapping function. According to Vinod (2011) many of the published genetic maps are based on Kosambi's distances. This Kosambi's classic received 3363 citations, 78 percent of which between 2000 and 2014. All citing articles published in 2014 that were available for content analysis (213 out of 249), refer to Kosambi's paper in their methods sections. It was very interesting to note that 208 mentioned Kosambi only once and always in the same context, e.g. "using Kosambi mapping function" or "employing the Kosambi function".

\section{DISCUSSION AND CONCLUSIONS}

Our citation study has shown that the papers published by two ceased eugenics journals have left a strong imprint on a variety of disciplines over time. This confirms the findings of Asknes (2003) that highly cited papers receive citations from "close and remote fields". A number of reasons may have led to such a high number of citations from 2000 to 2014, and the main reason may be new research impulses triggered by old articles. Even so, considering how much time has passed since their publishing, the continuing interest and the direct influence of these papers on contemporary researchers are quite exceptional. In the citation study on the famous Watson and Crick's paper, Ahmed et al. (2004) found that 75 percent of the citations were for historical or background reasons (mainly found in the introduction section). We expected our results to be similar to Oppenheim and Renn's (1978) who found that about 40 percent of citations were for purely historical reasons. But our in-depth content analysis of papers cited in 2014 has shown that the reasons for citing were fairly different. The share of citations for purely historical (Category 1) and/or background reasons (Category 2) is much lower, and citations for methodological reasons (Category 3) accounted for two thirds of all citations (Figure 1).

Four most cited papers seem to exemplify Donoho's (2002) list of paper writing recommendations for how to get cited a lot. At the top of the list is: "develop a method which can be applied on statistical data of a kind whose prevalence is growing rapidly", followed by "in developing a methodology, leave room for improvement". He argues that statisticians create a steady stream of methodology which can be used and cited in many other fields. The first half of the $20^{\text {th }}$ century, the period between 1920 and 1944 in particular, was overflowed with mathematical and statistical applications in biology, especially in quantitative genetics, like those by the pioneers Fisher and Wright. Regardless of their research topics, these most cited papers had developed particular research methodologies that become valuable instruments in many scientific disciplines. These papers in addition have continued to influence more recent studies to date and the citation count was still increasing in the last decades. 
The other highly cited papers in the period from 2000 onwards from our list are less outstanding, but this study clearly shows that even very old papers (aged 60-100 years) can play an active role in modern scientific world.

\section{ACKNOWLEDGEMENT}

This research received no specific grant from any funding agency in the public, commercial, or not-for profit sectors.

\section{REFERENCES}

Ahmed, T., Johnson, B., Oppenheim, C. and Peck, C. 2004. Highly cited old papers and the reasons why they continue to be cited. Part II., The 1953 Watson and Crick article on the structure of DNA. Scientometrics, Vol. 61, no. 2: 147-156.

Aksnes, D.W. 2003. Characteristics of highly cited papers. Research Evaluation, Vol. 12, no. 3: $159-170$.

Bornmann, L. and Daniel, H.D. 2008. What do citation counts measure? A review of studies on citing behavior. Journal of Documentation, Vol. 64, no. 1: 45-80.

Crow, J.F. 1989. Wright's theory of evolution - a citation classic commentary on The genetical structure of populations by Wright. S. Current Contents/Life Sciences, Vol. 32, no. 37: 17.

Davis, P.M. and Cochran, A. 2015. Cited half-life of the journal literature. Available at: http://arxiv.org/pdf/1504.07479v2.

Ding, Y., Zhang, G., Chambers, T., Song, M., Wang, X. and Zhai, C. 2014. Content-based citation analysis: the next generation of citation analysis. Journal of the Association for Information Science and Technology, Vol. 65, no. 9: 1820-1833.

Donoho, D. 2002. How to be a highly cited author in the mathematical sciences. In-cites. Available at: http://www.in-cites.com/scientists/DrDavidDonoho.html.

Fisher, R.A. 1936. The use of multiple measurements in taxonomic problems. Annals of Eugenics, Vol. 7, no. 2: 179-188.

Fisher, R.A. 1937. The wave of advance of advantageous genes. Annals of Eugenics, Vol. 7, no. 4: 355-369.

Fisher, R.A. 2012. R. A. Fisher is the most influential scientist ever. 2012. Simply Statistics. Available at: http://simplystatistics.org/2012/03/07/r-a-fisher-is-the-most-influentialscientist-ever.

Gaither, C.C. and Cavazos-Gaither, A.E. 2012. Gaither's dictionary of scientific quotations. New York: Springer: 684.

Garfield, E. 1975. The 'obliteration phenomenon' in science - and the advantage of being obliterated! Essays of an Information Scientist, Vol. 2: 396-398. Available at: http://garfield.library.upenn.edu/essays/v2p396y1974-76.pdf.

Gupta, B.M. 1997. Analysis of distribution of the age of citations in theoretical population genetics. Scientometrics, Vol. 40, no. 1: 139-162.

Hald, A. 2004. A history of parametric statistical inference from Bernoulli to Fisher, 1713 to 1935. Copenhagen: Department of Applied Mathematics and Statistics, University of Copenhagen. Available at: ftp://158.208.129.61/suzuki/Hald_Book.pdf.

Hanney, S., Frame, I., Grant, J., Buxton, M., Young, T. and Lewison, G. 2005. Using categorisations of citations when assessing the outcomes from health research. Scientometrics, Vol. 65, no. 3: 357-379.

Herlach, G. 1978. Can retrieval of information from citation indexes be simplified? Multiple mention of a reference as a characteristic of the link between cited and citing article. 
Journal of the American Society for Information Science, Vol.2 9, no. 6: 308-310.

Jin, X., Zhao, M., Chow, T.W.S. and Pecht, M. 2014. Motor bearing fault diagnosis using trace ratio linear discriminant analysis. IEEE Transactions on Industrial Electronics, Vol. 61, no. 5: 2441-2451.

Kim, K. and Lee, D. 2014. Inductive manifold learning using structured support vector machine. Pattern Recognition, Vol. 47, no. 1: 470-479.

Kosambi, D.D. 1944. The estimation of map distances from recombination values. Annals of Eugenics, Vol. 12: 172-175.

Larivière, V., Archambault, E. and Gingras, Y. 2008. Long-term variations in the aging of scientific literature: From exponential growth to steady-state science (1900-2004). Journal of the American Society for Information Science and Technology, Vol. 50, no. 2: 288-296.

Li, M., Pal, A., Phadke, A.G. and Thorp, J.S. 2014. Transient stability prediction based on apparent impedance trajectory recorded by PMUs. International Journal of Electrical Power and Energy Systems, Vol. 54: 498-504.

Maričić, S., Spaventi, J., Pavičić, L. and Pifat-Mrzljak G. 1998. Citation context versus the frequency counts of citation histories. Journal of the American Society for Information Science, Vol. 49, no. 6: 530-540.

Matulić, T. 2005. Bioetika i genetika: medicinska praksa između eugenike i jatrogene bolesti [Bioethics and genetics: medical practice between eugenics and iatrogenic disease]. Bogoslovska Smotra, Vol. 75, no. 1: 185-210. Available at: http://hrcak.srce.hr/file/38885.

McCain, K.W. and Turner, K. 1989. Citation context analysis and aging patterns of journal articles in molecular genetics. Scientometrics, Vol. 17, no. 1-2: 127-163.

Nava, R., Escalante-Ramirez, B., Cristóbal, G. and Estépar, R.S.J. 2014. Extended Gabor approach applied to classification of emphysematous patterns in computed tomography. Medical and Biological Engineering and Computing, Vol. 52, no. 4: 393403.

NLM Catalog. 2015. Available at: http://www.ncbi.nlm.nih.gov/nlmcatalog.

Norrgard, K. 2008. Human testing, the eugenics movement, and IRBs. Nature Education, Vol. 1, no. 1: 170. Available at: http://www.nature.com/scitable/topicpage/humantesting-the-eugenics-movement-and-irbs-724.

Oppenheim, C. and Renn, S.P. 1978. Highly cited old papers and the reasons why they continue to be cited. Journal of the American Society for Information Science, Vol. 29, no. 5: 225-231.

Paul, D.B. and Spencer, H.G. 1995. The hidden science of eugenics. Nature, Vol. 374, no. 6520: 302-304.

Pearl, R. 1927. The biology of superiority. American Mercury, Vol. 12, no. 47: 257-266.

Plomp, R. 1990. The significance of the number of highly cited papers as an indicator of scientific prolificacy. Scientometrics, Vol. 19, no. 3-4: 185-197.

Provine, W.B. 1986. Sewall Wright and evolutionary biology. Chicago: University of Chicago Press: 180.

Ramsden, E. 2006. Confronting the stigma of perfection: genetic demography, diversity and the quest for a democratic eugenics in the post-war United States. Working papers on the nature of evidence: how well do "facts" travel. No. 12/06. Available at: http://eprints.Ise.ac.uk/22536/1/1206Ramsden.pdf.

Thomson Reuters. Web of Science. 2015. Available at: http://webofknowledge.com.

Tome, J.A. and Carvalho, J.P. 2014. Fuzzy Boolean Nets - a nature inspired model for learning and reasoning. Fuzzy Sets and Systems, Vol. 253: 1-27.

Van Noorden, R., Maher, B. and Nuzzo, R. 2014. The top 100 papers. Nature, Vol. 514, no. 7524: 550-553. 
Verstak, A., Acharya, A., Suzuki, H., Henderson, S., lakhiaev, M., Lin, C.C.Y. and Shetty, N. 2014. On the shoulders of giants: the growing impact of older articles. Available at: http://arxiv.org/pdf/1411.0275.pdf.

Vinod, K.K. 2011. Kosambi and the genetic mapping function. Resonance, Vol. 16, no. 6: 540-550.

Voos, H. and Dagaev, K.S. 1976. Are all citations equal? Or, did we op. cit. your idem? Journal of Academic Librarianship, Vol. 1, no. 6: 19-21.

Weiss, K.M. and Lambert, B.W. 2011. When the time seems ripe: eugenics, the Annals, and the subtle persistence of typological thinking. Annals of Human Genetics, Vol. 75, no. 3: 334-343.

Wiesenthal, D.L. and Wiener, N.I. 1999. Ethical questions in the age of the new eugenics. Science and Engineering Ethics, Vol. 5, no. 3: 383-394.

Wikipedia contributors, "Fisher's equation," Wikipedia, The Free Encyclopedia. 2015. Available at: https://en.wikipedia.org/wiki/Fisher\%27s_equation.

Wikipedia contributors, " $h$-index," Wikipedia, The Free Encyclopedia. 2015. Available at: https://en.wikipedia.org/wiki/H-index.

Wikipedia contributors, "Linear discriminant analysis," Wikipedia, The Free Encyclopedia. 2015. Available at: https://en.wikipedia.org/wiki/Linear_discriminant_analysis.

Wikipedia contributors, "Ronald Fisher," Wikipedia, The Free Encyclopedia. 2015. Available at: https://en.wikipedia.org/wiki/Ronald_Fisher.

Wright, S. 1951. The genetical structure of populations. Annals of Eugenics, Vol. 15, no. 4: 323-354. 